\title{
Experimental study of combined low salinity and surfactant flooding effect on oil recovery
}

\author{
Abdulmecit Araz ${ }^{1}$ and Farad Kamyabi ${ }^{2, *}$ \\ ${ }^{1}$ Sabanci University, 34956 Istanbul, Turkey \\ ${ }^{2}$ Baku Higher Oil School, AZ1025 Baku, Azerbaijan
}

Received: 14 July 2020 / Accepted: 29 October 2020

\begin{abstract}
A new generation improved oil recovery methods comes from combining techniques to make the overall process of oil recovery more efficient. One of the most promising methods is combined Low Salinity Surfactant (LSS) flooding. Low salinity brine injection has proven by numerous laboratory core flood experiments to give a moderate increase in oil recovery. Current research shows that this method may be further enhanced by introduction of surfactants optimized for lowsal environment by reducing the interfacial tension. Researchers have suggested different mechanisms in the literature such as $\mathrm{pH}$ variation, fines migration, multicomponent ionic exchange, interfacial tension reduction and wettability alteration for improved oil recovery during lowsal injection.

In this study, surfactant solubility in lowsal brine was examined by bottle test experiments. A series of core displacement experiments was conducted on nine crude oil aged Berea core plugs that were designed to determine the impact of brine composition, wettability alteration, Low Salinity Water (LSW) and LSS flooding on Enhancing Oil Recovery (EOR). Laboratory core flooding experiments were conducted on the samples in a heating cabinet at $60{ }^{\circ} \mathrm{C}$ using five different brine compositions with different concentrations of $\mathrm{NaCl}_{1} \mathrm{CaCl}_{2}$ and $\mathrm{MgCl}_{2}$. The samples were first reached to initial water saturation, $S_{\text {wi }}$, by injecting connate water (high salinity water). LSW injection followed by LSS flooding performed on the samples to obtain the irreducible oil saturation.

The results showed a significant potential of oil recovery with maximum additional recovery of $7 \%$ Original Oil in Place (OOIP) by injection of LS water (10\% LS brine and $90 \%$ distilled water) into water-wet cores compared to high salinity waterflooding. It is also concluded that oil recovery increases as wettability changes from water-wet to neutral-wet regardless of the salinity compositions. A reduction in residual oil saturation, $S_{\text {or }}$, by 1.1-4.8\% occurred for various brine compositions after LSS flooding in tertiary recovery mode. The absence of clay swelling and fine migration has been confirmed by the stable differential pressure recorded for both LSW and LSS flooding. Aging the samples at high temperature prevented the problem of fines production. Combined LSS flooding resulted in an additional oil recovery of $9.2 \%$ OOIP when applied after LSW flooding.

Surfactants improved the oil recovery by reducing the oil-water interfacial tension. In addition, lowsal environment decreased the surfactant retention, thus led to successful LSS flooding. The results showed that combined LSS flooding may be one of the most promising methods in EOR. This hybrid improved oil recovery method is economically more attractive and feasible compared to separate low salinity waterflooding or surfactant flooding.
\end{abstract}

\section{Introduction}

It is generally recognized that after the primary and secondary recovery mechanisms carried out in an oil reservoir, up to two third of the crude oil remains trapped in the reservoirs due to the dominating capillary forces or poor sweep efficiency of the injection fluid. In order to mobilize the

\footnotetext{
* Corresponding author: faradk@bhos.edu.az
}

trapped oil and increase the drainage efficiency, more effective and advanced recovery methods must be implemented.

Water flooding is the most frequently applied secondary method in Enhanced Oil Recovery (EOR) after natural depletion to maintain the reservoir pressure and mobilize the remained oil in the reservoir. In the past, little intention has been given to the salinity and the ion composition of the injection water and on its effect on oil recovery. The first study carried on by Martin [1] on the effect of injection brine composition and showed that decreasing the salinity 
leads to higher oil recovery due to migration of clay particles. Almost a decade later, Bernard [2] performed a comprehensive study by implementing laboratory experiments on Berea sandstone cores showing improved oil recovery by lowering salinity of the injection brine. Since then, there has been growing interest in understanding the Low Salinity Water (LSW) flooding mechanism which announced to be an emerging EOR method [3].

In the last decades, it has been proven by both laboratory and field tests that reducing the salinity of the injected water leads to higher oil recovery [4]. Jadhunandan and Morrow [5] showed that wettability affects waterflooding mechanism in Crude/Oil/Brine/Rock (COBR) systems. After carrying out wide-range of experiments based on 50 Berea sandstone cores and different salt concentrations, they have concluded that adjustment of the injection brine composition for mature waterflood offers a possible and economically realistic method for improving oil recovery by wettability alteration. Tang and Morrow [6-8] and Morrow et al. [9] studied the effect of brine composition on oil recovery extensively in series of displacement experiments using different crude oils and Reservoir Brine (RB) diluted by factors of 10 and 100 where $12 \%$ reduction in residual oil saturation $\left(S_{\text {or }}\right)$ was established.

Low Salinity Water was designated as an Improved Oil Recovery (IOR) process at the SPE/DOE Symposium on IOR, Tulsa, in 2006. Since that time, there has been a growing interest in understanding the underlying mechanism behind low salinity effect and extensive body of experimental works such as Single Well Tracer Tests (SWTT) and Log-Inject-Log (LIL) techniques have been introduced. Many laboratory works performed prior to application of LSW in field scale. However, most of them are not reported in the public literature [10]. The mechanism of LSW flooding is not fully understood despite the growing research and interest on LSE in reservoir conditions. Many outcrop sandstones meeting the conditions of LSW have not shown any increase in oil recovery $[11,12]$. Further research in both laboratory and field scales is necessary for a better understanding of the basics behind the underlying mechanism of low salinity effect. This will also encourage the investigation of other IOR methods such as surfactant and polymer flooding and their potential in low salinity environment [13].

Surfactant flooding is a chemical EOR technique used to achieve higher oil recovery by reducing the Interfacial Tension (IFT) between oil and water, thus mobilizing capillary trapped oil. Salinity environment affects the efficiency of surfactants. Surfactants efficiency in lowering the IFT depends on several factors such as brine concentration. Therefore, surfactants combined with low salinity flooding implemented as a new hybrid model due to low cost and commercial availability.

This paper studies the effect of combined low salinity and surfactant injection on oil recovery using nine Berea sandstone cores. Low salinity waterflooding with different brine compositions applied to the samples as a secondary recovery method, followed by Low Salinity Surfactant (LSS) flooding at $60{ }^{\circ} \mathrm{C}$. Throughout the experimental work, the density of the brine concentrations as well as
Table 1. Mineralogy of Berea sandstone samples.

\begin{tabular}{lccc}
\hline Sample & Quartz (\%) & Alkali feldspar (\%) & Pyroxene (\%) \\
\hline 1 & 93 & 6 & $<1$ \\
2 & 91 & 8 & $<1$ \\
3 & 92 & 8 & $<1$ \\
4 & 93 & 7 & $<1$ \\
5 & 91 & 8 & $<1$ \\
\hline
\end{tabular}

permeability and porosity measurements of the cores are measured together with the study of the phase behavior of the surfactant to provide better understanding of the concepts behind waterflooding.

\section{Experimental materials and setup}

Experiments were conducted on nine Berea sandstone core plugs taken from the same block to ensure similar properties for all cores used in the analysis. Core plugs were designated as B1-B1, B2-B2, B3-B3, B4-B4, B5-B5, B5-B1, B5-B2, $\mathrm{B} 5-\mathrm{B} 3$, and $\mathrm{B} 5-\mathrm{B} 4$. These names were given according to the core saturation and LSW/LSS flooding order. For example, in B5-B1, the first B indicates that the core is saturated with brine 5 , and the second B stands for LSW/LSS flooding done using brine 1 . The samples were first drained with connate water (high salinity water) until initial water saturation, $S_{\mathrm{wi}}$, is established. LSW injection followed by LSS flooding performed on the samples to obtain the irreducible oil saturation. Both LSW and LSW flooding carried out on the samples in a heating cabinet at $60{ }^{\circ} \mathrm{C}$. For a better understanding of the conducted LSW and LSS flooding experiment rock and fluid analysis such as porosity, permeability, density measurements were carried out on the samples.

\subsection{Berea sandstone}

In core flooding analyses, Berea sandstones are considered to be standard experimental material. The mineralogy of Berea plugs was characterized by X-Ray Diffraction (XRD) analysis carried out on the five samples taken from block 6 . It was assumed that the obtained mineralogy was representative for all the core samples. These samples mostly contained quartz, alkali feldspar and pyroxene as given in Table 1.

\subsection{Brine}

Injection brines used in the experiments were made by dissolving different salts in deionized water to prepare five different compositions listed in Table 2. All brines were filtered using a $0.45 \mu \mathrm{m}$ vacuum filter in order to remove the particles and/or any undesired obstacles from the composition. Total Dissolved Solid (TDS) concentration in brine ranged from 29000 to $32500 \mathrm{ppm}$. As typical formation water contains both divalent and monovalent ions, high salinity water was used to establish initial water saturation, while 
Table 2. Brine composition.

\begin{tabular}{|c|c|c|c|c|c|c|c|c|c|}
\hline Brine & Composition (\%) & $\begin{array}{l}\mathrm{NaCl} \\
(\mathrm{g} / \mathrm{L}) \\
\end{array}$ & $\begin{array}{c}\mathrm{CaCl}_{2}: 2 \mathrm{H}_{2} \mathrm{O} \\
(\mathrm{g} / \mathrm{L})\end{array}$ & $\begin{array}{c}\mathrm{MgCl}_{2}: 2 \mathrm{H}_{2} \mathrm{O} \\
(\mathrm{g} / \mathrm{L}) \\
\end{array}$ & $\begin{array}{l}\mathrm{Na}^{+} \\
(\mathrm{ppm}) \\
\end{array}$ & $\begin{array}{c}\mathrm{Ca}^{+} \\
(\mathrm{ppm}) \\
\end{array}$ & $\begin{array}{c}\mathrm{Mg}^{+} \\
(\mathrm{ppm}) \\
\end{array}$ & $\begin{array}{c}\mathrm{Cl}^{-} \\
(\mathrm{ppm}) \\
\end{array}$ & $\begin{array}{l}\text { TDS } \\
(\mathrm{ppm}) \\
\end{array}$ \\
\hline B1 & $100 \mathrm{NaCl}$ & 32.50 & - & - & 12785 & - & - & 19715 & 32500 \\
\hline B2 & $95 \mathrm{NaCl}, 5 \mathrm{CaCl}_{2}$ & 30.875 & 1.362 & - & 11507 & 741.5 & - & 19055 & 31303 \\
\hline B3 & $95 \mathrm{NaCl}, 5 \mathrm{MgCl}_{2}$ & 30.875 & - & 1.885 & 11507 & - & 450.7 & 19058 & 31015 \\
\hline B4 & $\begin{array}{c}90 \mathrm{NaCl}, 5 \mathrm{CaCl}_{2}, 5 \\
\mathrm{MgCl}_{2}\end{array}$ & 29.250 & 1.362 & 1.885 & 10228 & 741.5 & 450.7 & 18398 & 29818 \\
\hline B5 & $\begin{array}{c}90 \mathrm{NaCl}, 9 \mathrm{CaCl}_{2}, 1 \\
\mathrm{MgCl}_{2}\end{array}$ & 29.250 & 2.210 & 0.305 & 10228 & 1335.8 & 89.7 & 18396 & 30050 \\
\hline
\end{tabular}

Key: LS water was obtained by $1 / 10$ dilutions of the brines in the list.

low salinity brines were chosen to have $10 \%$ of the listed compositions added to $90 \%$ of distilled water. LSS was prepared by adding sodium dodecyl benzene sulfonate to LSW solution.

\subsection{Oil}

During the drainage and flooding experiments, crude oil A was used to establish the minimum value of initial water saturation, $S_{\mathrm{wi}}$, for all cores. Crude oil densities were measured at $15{ }^{\circ} \mathrm{C}$ and $60{ }^{\circ} \mathrm{C}$ while viscosities were obtained at $20^{\circ} \mathrm{C}$ and $60^{\circ} \mathrm{C}$. The bulk composition obtained by SARA (Saturates/Aromatics/Resins/Asphaltenes) analysis, Acid Number (AN) and Base Number (BN) were analyzed. Crude oil was also used in aging the cores before the main flooding experiment. Composition and some of the important properties of crude oil A are listed in Table 3 [14].

Oil viscosity at $60{ }^{\circ} \mathrm{C}$ was noticeably lower compared to the correspondent viscosity at $20{ }^{\circ} \mathrm{C}$. It should be noted that the drainage process was carried out at room temperature different from the flooding experiment performed at $60{ }^{\circ} \mathrm{C}$.

\subsection{Surfactant}

Sodium Dodecyl Benzene Sulfonate (SDBS) was dissolved in brine to prepare low salinity surfactant. SDBS, a white anionic surfactant with powder density of $0.18 \mathrm{~g} / \mathrm{mL}$ and molecular formula of $\mathrm{C}_{18} \mathrm{H}_{29} \mathrm{NaO}_{3} \mathrm{~S}$. It is difficult to solve the surfactant in brine. Therefore, for each experiment, the surfactant was mixed with low salinity brine only after warming it up to $60^{\circ} \mathrm{C}$.

\subsection{Bottle test}

Precipitation of the surfactant is an undesired process during combination of low salinity waterflooding with surfactant injection. In order to examine the concentration range in which the surfactant does not precipitate, brine solutions with 300, 500, 1000 and $3000 \mathrm{ppm}$ were warmed up to $60{ }^{\circ} \mathrm{C}$ and mixed with the surfactant (SDBS).

\subsection{Core preparation}

To avoid any experimental error, cores were prepared very carefully. All cores were cut consistently in the same range
Table 3. Compositions and properties of crude oil A.

\begin{tabular}{ll}
\hline Composition $(\%)$ & \\
\hline 61.19 & Saturates \\
32.42 & Aromatics \\
4.93 & Resins \\
1.46 & Alphaltenes \\
$\mathrm{AN}(\mathrm{mg} \mathrm{KOH} / \mathrm{g})$ & 1.08 \\
$\mathrm{BN}(\mathrm{mg} \mathrm{KOH} / \mathrm{g})$ & 1.16 \\
Density $\left(\mathrm{g} / \mathrm{cm}^{3}\right)$ & $0.86 @ 15^{\circ} \mathrm{C}$ \\
& $0.83 @ 60^{\circ} \mathrm{C}$ \\
API gravity & 33.4 \\
Viscosity $(\mathrm{cP})$ & $19.90 @ 20^{\circ} \mathrm{C}$ \\
& $4.07 @ 60{ }^{\circ} \mathrm{C}$ \\
\hline
\end{tabular}

with the lengths of approximately $10 \mathrm{~cm}$ and a diameter of $3.8 \mathrm{~cm}$. Before starting to carry out any measurement, the cores were cleaned with a brush to remove possible dust particles attached to the surface of the samples. Afterwards, they were inserted inside Soxhlet apparatus to be extracted with methanol for $24 \mathrm{~h}$.

After the samples were cleansed with methanol, they were placed in the heating cabinet at $60{ }^{\circ} \mathrm{C}$ for one week. Water drops removal was assured after this step. Following the drying process, weight of each sample was measured with a scale of 0.001 error sensitivity.

\subsection{Permeability measurements}

Permeability measurements were conducted based on Darcy equation which relates the absolute permeability of the rock to the dimensions of the sample, viscosity of the fluid and the pressure drop along the sample. Thus, the sample was inserted inside a coreholder under constant pressure drop of 0.5 bar and the flow rate was recorded. Standard value for air viscosity was taken as $0.0179 \mathrm{cP}$.

In 1941, Klinkenberg concluded that the measured permeability can be bigger than the true permeability of the rock at low pressures when gases are used as flowing fluid. Thus, he suggested a procedure for calibration of permeability data obtained from measurement device. According to the suggested formula, absolute permeability $\left(K_{\text {abs }}\right)$ can be calculated by extrapolating the line to infinite mean 


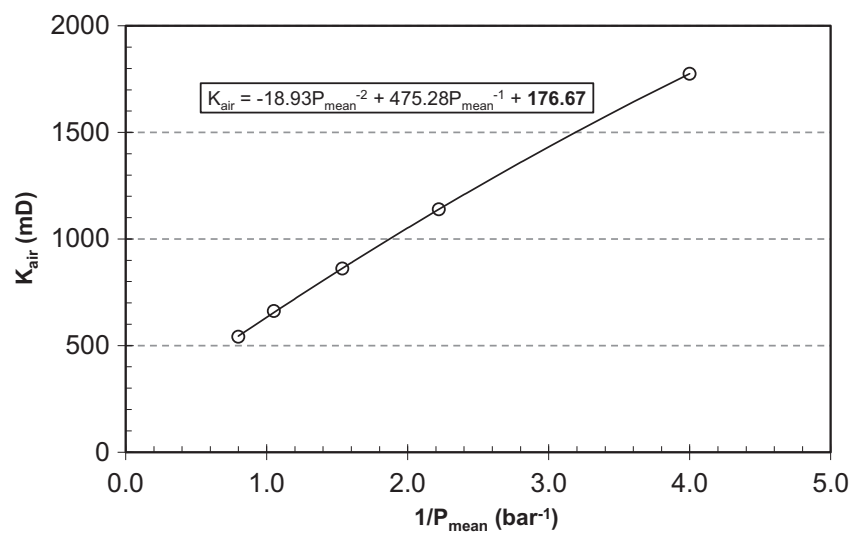

Fig. 1. Klinkenberg permeability correction for B1-B1.

pressure in the plot of air permeability $\left(K_{\text {air }}\right)$ versus inverse mean core pressure. Figure 1 demonstrates that the value of $K_{\text {abs }}$ for B1-B1 sample is equal to $176.67 \mathrm{mD}$.

\subsection{Porosity measurements}

In this experiment, helium porosimeter, which takes the advantage of Boyle's law, was used to determine the porosity of the core samples. To do so, bulk and grain volumes of the samples were measured. Bulk volume was calculated using the dimensions of the core while grain volume was evaluated using the reference and final volumes of the chambers (Fig. 2). Samples were inserted inside the chamber volume of $170 \mathrm{~cm}^{3}$, and helium was applied to the core until the pressure caliber was regulated. The value of the applied volume was reported and subtracted from the chamber volume to get the grain volume. Measured porosity by Helium porosimeter was ranged from 15.40 to $19.10 \%$.

\subsection{Cores saturation}

The Berea sandstone cores were saturated using a vacuum pump. Before inserting the sample inside the cap, the machine was run for approximately $20 \mathrm{~min}$ to clean all the lines (vacuum and drainage) and regulate the pressure. The samples were placed inside the container carefully together with the porous plates. After the vacuum was applied for about $30 \mathrm{~min}$ for the purpose of cleaning, warming, pressure regulation and safety issues, the already prepared brine samples were poured into the funnel. Both the core and porous plate was drained thanks to gravity and vacuum forces.

\subsection{Initial water saturation}

Initial water saturation was established at ambient temperature using porous plate shown in Figure 3. To achieve homogeneous saturation distribution, crude oil was injected to the fully brine-saturated core sample inserted into the coreholder. Beneath the sample, a small porous plate saturated with the same brine was placed. A sleeve pressure (5) was applied and increased gradually. The displacement of brine through the core occurred by introducing back

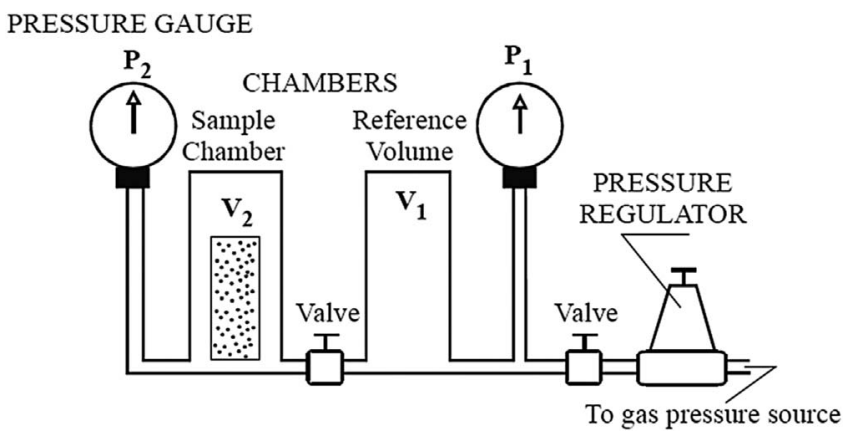

Fig. 2. Schematic diagram of helium porosimeter apparatus [15].

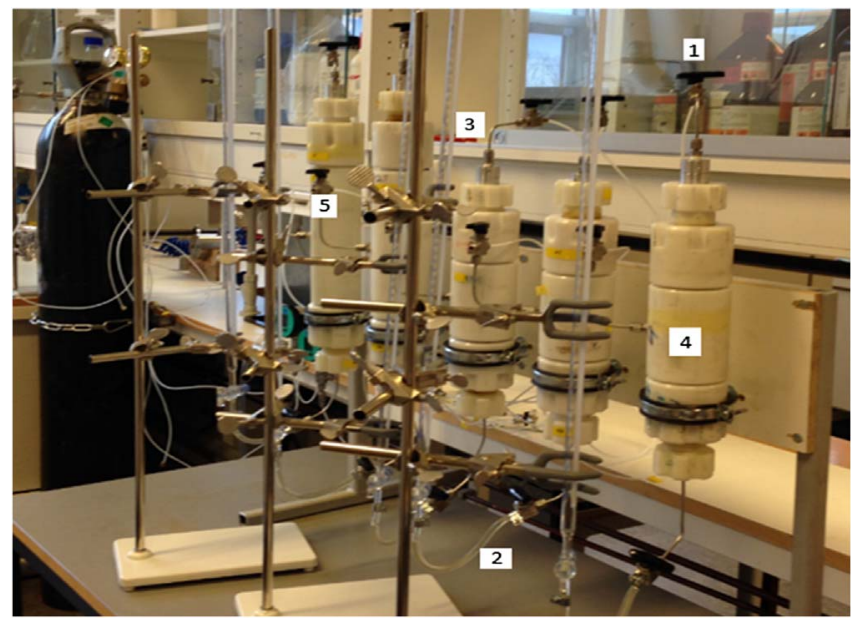

Fig. 3. Porous plate apparatus.

pressure (1). As initial water saturation was calculated using the produced water volume of brine and the Pore Volume (PV) of the core, a graduated cylinder (3) was connected to the bottom of the coreholder (4) with plastic pipe (2) to measure the produced volume of brine.

\subsection{Core aging}

After the cores were flooded by crude oil, they were inserted into the cells and placed in a heat cabin at $80{ }^{\circ} \mathrm{C}$ for three weeks in order to alter the wettability from strongly waterwet condition. The main reason behind using high temperature was to enhance the Crude Oil-Brine-Rock (COBR) interactions. Afterwards, the cores were taken from the cells directly to the coreholder for performing the flooding experiment.

\subsection{Flooding procedure}

The flooding apparatus given in Figure 4 was used. The tubes and coreholder were cleansed before starting the flooding. Afterwards, the cores were taken from the aging cell and inserted inside the Hassler coreholder. The experiment was performed at $60{ }^{\circ} \mathrm{C}$, and 20 bars sleeve pressure 


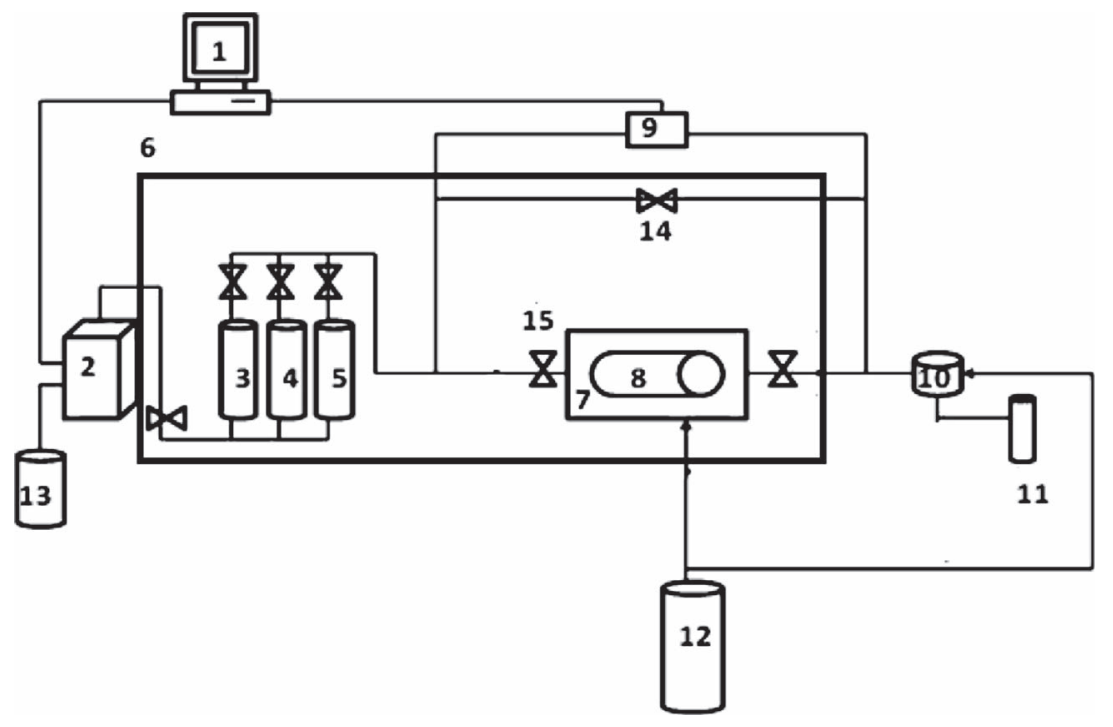

1. Computer

2. Quizix pump

3. Low salinity brine reservoir

4. Low salinity surfactant reservoir

5. Oil reservoir

6. Heating cabinet

7. Hassler coreholder

8. Core plug

9. Differential pressure transmitter

10. Back pressure regulator

11. Effluent collector

12. High pressure nitrogen cylinder

13. Pump inlet

14. Check valve

15. Regular valve

Fig. 4. Schematic of coreflooding apparatus [16].

Table 4. Tests with same composition in injection and in-situ brines.

\begin{tabular}{cccl}
\hline Test & $\begin{array}{c}\text { In-situ } \\
\text { brine }\end{array}$ & $\begin{array}{c}\text { LSW } \\
\text { flooding }\end{array}$ & \multicolumn{1}{c}{ LSS flooding } \\
\hline $1-1$ & B1 & $(1 / 10)$ B1 & Surfactant in $(1 / 10)$ B1 \\
$1-2$ & B2 & $(1 / 10)$ B2 & Surfactant in $(1 / 10)$ B2 \\
$1-3$ & B3 & $(1 / 10)$ B3 & Surfactant in $(1 / 10)$ B3 \\
$1-4$ & B4 & $(1 / 10)$ B4 & Surfactant in $(1 / 10)$ B4 \\
$1-5$ & B5 & $(1 / 10)$ B5 & Surfactant in $(1 / 10)$ B5 \\
\hline
\end{tabular}

was added gradually. The back pressure was set to 3 bar to avoid gas liberation and any back flow at high temperature. The pump (positive displacement Quizix pump) was displacing fluid (brine, oil) from the reservoirs to the core plug (number 8 in Fig. 4). To represent a typical reservoir velocity, flooding rate of $12 \mathrm{~mL} / \mathrm{h}$ equivalent to interstitial velocity range from 1.34 up to $1.66 \mathrm{~m} /$ day was chosen for flooding the core plugs. The pressure drop was monitored continuously during the injection by differential pressure transmitter connected to the inlet and outlet of the Hassler coreholder. Produced liquids were collected in $5 \mathrm{~mL}$ effluent tubes at ambient temperature and atmospheric pressure.

LSW and LSS floodings were performed sequentially for $15 \mathrm{~h}$ each. To ensure recovering all oil inside the core samples, the injection continued for 2-3 PV after both floodings, despite the stop in oil production. Tables 4 and 5 provide summary of in-situ and injected brine compositions for each test.

\section{Experimental results}

Laboratory coreflooding experiments were conducted at $60{ }^{\circ} \mathrm{C}$ using Berea sandstone coreplugs and five different brine compositions with various concentrations of $\mathrm{NaCl}$, $\mathrm{CaCl}_{2}$ and $\mathrm{MgCl}_{2}$.
Table 5. Tests with different composition in injection and in-situ brine.

\begin{tabular}{cccc}
\hline Test & $\begin{array}{c}\text { In-situ } \\
\text { brine }\end{array}$ & $\begin{array}{c}\text { LSW } \\
\text { flooding }\end{array}$ & \multicolumn{1}{c}{ LSS flooding } \\
\hline $2-1$ & B5 & $(1 / 10)$ B1 & Surfactant in $(1 / 10)$ B1 \\
$2-2$ & B5 & $(1 / 10)$ B2 & Surfactant in $(1 / 10)$ B2 \\
$2-3$ & B5 & $(1 / 10)$ B3 & Surfactant in $(1 / 10)$ B3 \\
$2-4$ & B5 & $(1 / 10)$ B4 & Surfactant in $(1 / 10)$ B4 \\
\hline
\end{tabular}

\subsection{Bottle test results}

The surfactant concentration should be as high as possible to maximize the surfactant effect, but not too high to prevent surfactant precipitation. The observations of bottle test experiment performed at $60{ }^{\circ} \mathrm{C}$ to determine the optimum concentration of the surfactant in LSS flooding are given in Table 6.

As it can be seen from Table 6, brines B1 and B4 showed no precipitation at any of the concentrations at the heating cabinet temperature. However, brines B2, B3 and B5 showed some cloudy solution or precipitation at the concentrations of 1000 and/or $3000 \mathrm{ppm}$. Since, in this study, using the same concentration for all brine compositions was preferred, the brine concentration of $500 \mathrm{ppm}$ was selected for the flooding experiments.

\subsection{Core properties}

For clear understanding of the impact of LSW and LSS on oil recovery, it is important to have similar core physical properties in the experiment. Table 7 lists the properties of the 9 cores selected out of total 23 cores taken from block 6 .

As shown in Figure 3, five coreholders were used in the porous plate apparatus. The experiments to establish $S_{\mathrm{wi}}$ were therefore conducted in two rounds. In the first round, 
Table 6. Summary of bottle test experiment for different brines at $60{ }^{\circ} \mathrm{C}$.

\begin{tabular}{|c|c|c|c|c|c|}
\hline \multirow[t]{2}{*}{ Brine } & \multirow[t]{2}{*}{ SDBS (ppm) } & \multicolumn{4}{|c|}{ Waiting time in heating cabinet } \\
\hline & & 1 day & 2 days & 3 days & 7 days \\
\hline \multirow[t]{4}{*}{ B1 } & 300 & $\mathrm{~S}, \mathrm{NP}$ & $\mathrm{S}, \mathrm{NP}$ & $\mathrm{S}, \mathrm{NP}$ & $\mathrm{S}, \mathrm{NP}$ \\
\hline & 500 & $\mathrm{~S}, \mathrm{NP}$ & $\mathrm{S}, \mathrm{NP}$ & $\mathrm{S}, \mathrm{NP}$ & $\mathrm{S}, \mathrm{NP}$ \\
\hline & 1000 & $\mathrm{~S}, \mathrm{NP}$ & $\mathrm{S}, \mathrm{NP}$ & $\mathrm{S}, \mathrm{NP}$ & $\mathrm{S}, \mathrm{NP}$ \\
\hline & 3000 & $\mathrm{~S}, \mathrm{NP}$ & $\mathrm{S}, \mathrm{NP}$ & $\mathrm{S}, \mathrm{NP}$ & $\mathrm{S}, \mathrm{NP}$ \\
\hline \multirow[t]{4}{*}{ B2 } & 300 & $\mathrm{~S}, \mathrm{NP}$ & $\mathrm{S}, \mathrm{NP}$ & $\mathrm{S}, \mathrm{NP}$ & $\mathrm{S}, \mathrm{NP}$ \\
\hline & 500 & $\mathrm{~S}, \mathrm{NP}$ & $\mathrm{S}, \mathrm{NP}$ & $\mathrm{S}, \mathrm{NP}$ & $\mathrm{S}, \mathrm{NP}$ \\
\hline & 1000 & $\mathrm{~S}, \mathrm{NP}$ & $\mathrm{PB}, \mathrm{NP}$ & $\mathrm{PB}, \mathrm{NP}$ & $\mathrm{LP}$ \\
\hline & 3000 & LC, NP & $\mathrm{C}, \mathrm{NP}$ & $\mathrm{C}, \mathrm{NP}$ & $\mathrm{P}$ \\
\hline \multirow[t]{4}{*}{ B3 } & 300 & $\mathrm{~S}, \mathrm{NP}$ & $\mathrm{S}, \mathrm{NP}$ & $\mathrm{S}, \mathrm{NP}$ & $\mathrm{S}, \mathrm{NP}$ \\
\hline & 500 & $\mathrm{~S}, \mathrm{NP}$ & $\mathrm{S}, \mathrm{NP}$ & $\mathrm{S}, \mathrm{NP}$ & $\mathrm{S}, \mathrm{NP}$ \\
\hline & 1000 & $\mathrm{~S}, \mathrm{NP}$ & $\mathrm{S}, \mathrm{NP}$ & $\mathrm{C}, \mathrm{NP}$ & $\mathrm{C}, \mathrm{NP}$ \\
\hline & 3000 & $\mathrm{~S}, \mathrm{NP}$ & LC, NP & $\mathrm{C}, \mathrm{NP}$ & $\mathrm{C}, \mathrm{NP}$ \\
\hline \multirow[t]{4}{*}{ B4 } & 300 & $\mathrm{~S}, \mathrm{NP}$ & $\mathrm{S}, \mathrm{NP}$ & $\mathrm{S}, \mathrm{NP}$ & $\mathrm{S}, \mathrm{NP}$ \\
\hline & 500 & $\mathrm{~S}, \mathrm{NP}$ & $\mathrm{S}, \mathrm{NP}$ & $\mathrm{S}, \mathrm{NP}$ & $\mathrm{S}, \mathrm{NP}$ \\
\hline & 1000 & $\mathrm{~S}, \mathrm{NP}$ & $\mathrm{S}, \mathrm{NP}$ & $\mathrm{S}, \mathrm{NP}$ & $\mathrm{S}, \mathrm{NP}$ \\
\hline & 3000 & $\mathrm{~S}, \mathrm{NP}$ & $\mathrm{S}, \mathrm{NP}$ & $\mathrm{S}, \mathrm{NP}$ & $\mathrm{S}, \mathrm{NP}$ \\
\hline \multirow[t]{4}{*}{ B5 } & 300 & $\mathrm{~S}, \mathrm{NP}$ & $\mathrm{S}, \mathrm{NP}$ & $\mathrm{S}, \mathrm{NP}$ & $\mathrm{S}, \mathrm{NP}$ \\
\hline & 500 & $\mathrm{~S}, \mathrm{NP}$ & $\mathrm{S}, \mathrm{NP}$ & $\mathrm{S}, \mathrm{NP}$ & $\mathrm{S}, \mathrm{NP}$ \\
\hline & 1000 & $\mathrm{~S}, \mathrm{NP}$ & $\mathrm{S}, \mathrm{NP}$ & $\mathrm{S}, \mathrm{NP}$ & $\mathrm{S}, \mathrm{NP}$ \\
\hline & 3000 & $\mathrm{~S}, \mathrm{NP}$ & LC, NP & $\mathrm{PB}, \mathrm{NP}$ & $\mathrm{P}, \mathrm{VLP}$ \\
\hline
\end{tabular}

Key: $\mathrm{S}=$ Dissolved; $\mathrm{NP}=$ No precipitation; $\mathrm{LC}=$ Less cloudy; $\mathrm{PB}=$ Particles in the bottom; $\mathrm{C}=\mathrm{Cloudy}$; $\mathrm{P}=$ Precipitation $; \mathrm{LP}=$ Low precipitation; $\mathrm{VLP}=$ Very low precipitation.

Table 7. Summary of cores properties.

\begin{tabular}{lcccccc}
\hline Core ID & Length $(\mathrm{cm})$ & Diameter $(\mathrm{cm})$ & Bulk volume $\left(\mathrm{cm}^{3}\right)$ & $K_{\text {abs }}(\mathrm{mD})$ & Porosity $(\%)$ & $S_{\text {wi }}(\%)$ \\
\hline B1-B1 & 9.942 & 3.798 & 112.63 & 176.7 & 16.32 & 22.0 \\
B2-B2 & 9.953 & 3.797 & 112.70 & 217.8 & 16.34 & 23.0 \\
B3-B3 & 9.939 & 3.786 & 111.89 & 172.3 & 15.73 & 21.0 \\
B4-B4 & 9.947 & 3.798 & 112.69 & 177.5 & 15.40 & 24.0 \\
B5-B5 & 9.940 & 3.795 & 112.43 & 154.4 & 17.77 & 25.0 \\
B5-B1 & 9.950 & 3.803 & 113.02 & 198.0 & 17.60 & 27.0 \\
B5-B2 & 9.947 & 3.779 & 111.59 & 191.9 & 15.64 & 28.0 \\
B5-B3 & 9.938 & 3.785 & 111.82 & 285.6 & 16.71 & 21.0 \\
B5-B4 & 9.941 & 3.808 & 113.21 & 300.8 & 18.94 & 22.0 \\
\hline
\end{tabular}

cores B1-B1, B2-B2, B5-B1, B5-B2, and B5-B5 were placed into the porous plate for 16 days. Due to the leakage in the B5-B1 part of the porous plate, the measured saturation values for this core showed some inconsistency. This unexpected experimental error also affected the results of core B5-B2 which eventually caused variations in the results of the other cores used in this round of experiment as sleeve and injection pressures in the setup were connected to the B5-B2 coreholder. In the second round, $S_{\mathrm{wi}}$ values for cores B3-B3, B4-B4, B5-B3 and B5-B4 were determined. Fortunately, no leakage was observed in this round of experiment, and, as Table 7 demonstrates, consistent $S_{\text {wi }}$ results were obtained.

\subsection{Flooding experiments and production profiles}

Each core was flooded with 10 PV of LSW followed by 10 PV of LSS. To ensure the recovery of all remaining oil, LSS injection has been extended for additional 2-3 PV. Core flooding results are studied in terms of the injection brine and ultimate oil recovery. The recovery curves for the first and second rounds of the flooding experiment are plotted in Figures 5 and 6, respectively. To ease the interpretation and focus on the key purpose of this study, oil recovery values up to $45 \%$ Original Oil in Place (OOIP), which were practically identical for all the core samples, are not shown in the figures. 


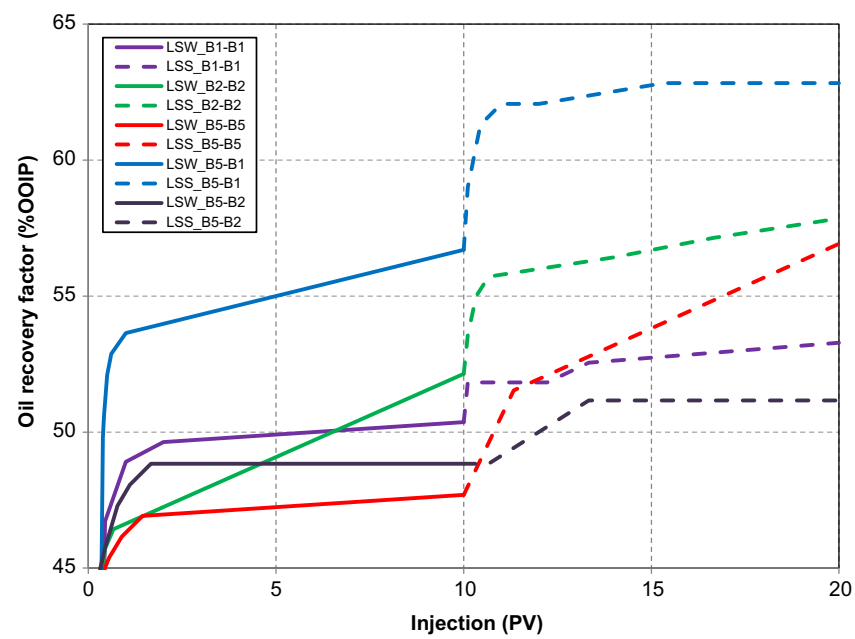

Fig. 5. Recovery curves for cores in first round of flooding experiment.

As shown in the figures, the cores were first flooded with various LSW (indicated by solid lines). Afterwards, in order to further reduce residual oil saturation, the injection continued with LSS (indicated by dashed lines) only after injecting 10 PV LSW. Therefore, after switching the flooding process to LSS, due to the possible existing amount of LSW in the pipes and production tubes and also for precise determination of LSS flooding efficiency, the oil produced from the first 0.15 PV LSS flooding was considered to be a result of LSW flooding.

Lowsal water injection starting from initial water saturation resulted in oil recovery ranged between $46 \%$ and $57 \%$ OOIP. The highest oil recovery was achieved in B5-B1, $56.7 \%$ OOIP, where the core saturated with B5 $(9 \% \mathrm{NaCl}$, $0.9 \% \mathrm{CaCl}_{2}$ and $\left.0.1 \% \mathrm{MgCl}_{2}\right)$ and flooded with $\mathrm{B} 1(10 \%$ $\mathrm{NaCl})$. Also, $S_{\text {wi }}$, was the lowest $(10.8 \%)$ for B5-B1 due to the leakage occurred during the establishment of initial water saturations.

Continuous injection of LSS solution resulted in high incremental oil recovery ranged between $1.5 \%$ and $9.2 \%$ OOIP. The increment in oil recovery may be explained reasonably on a basis of interactions between surfactant solution and rock surface, i.e., retention, which in turn is closely associated with surfactant concentration [17]. The highest oil recovery increments were observed in B2-B2, B4-B4 and B5-B5, 5.71\%, 5.94\% and 9.2\% OOIP respectively. A possible optimal oil recovery can be obtained by LSW injection of B2 followed by LSS flooding using B5. As it can be seen from Figure 7, the highest oil recovery for LSS flooding was obtained by injecting B5, while injection of $\mathrm{B} 2$ resulted in the maximum oil production for LSW flooding.

Generally, if the oil recovery result of B5-B1 is excluded due to the unreliable $S_{\mathrm{wi}}$ value, the highest oil recoveries were obtained for the cores in which the same brine composition is used for both saturating the core and flooding (B1-B1, B2-B2 and B3-B3). The oil recoveries for the rest

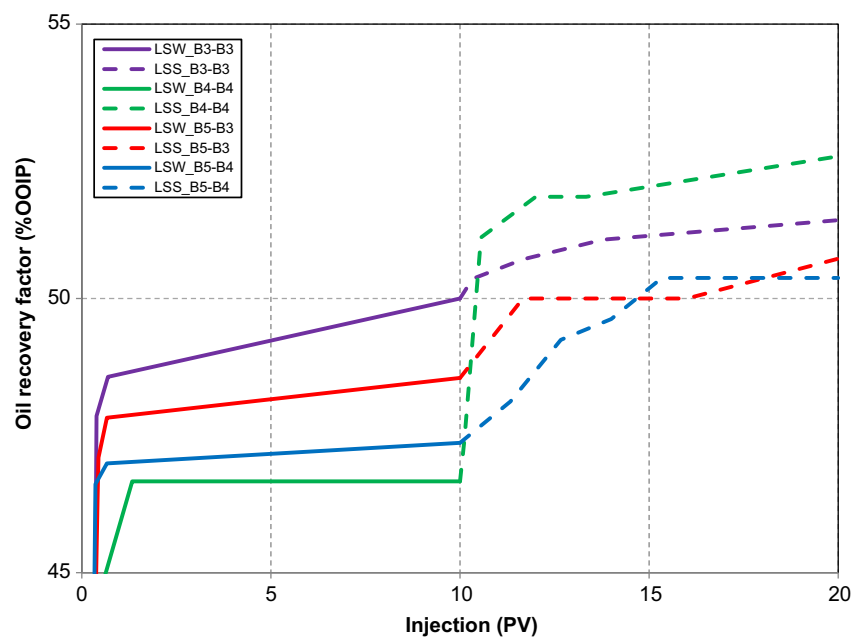

Fig. 6. Recovery curves for cores in second round of flooding experiment.

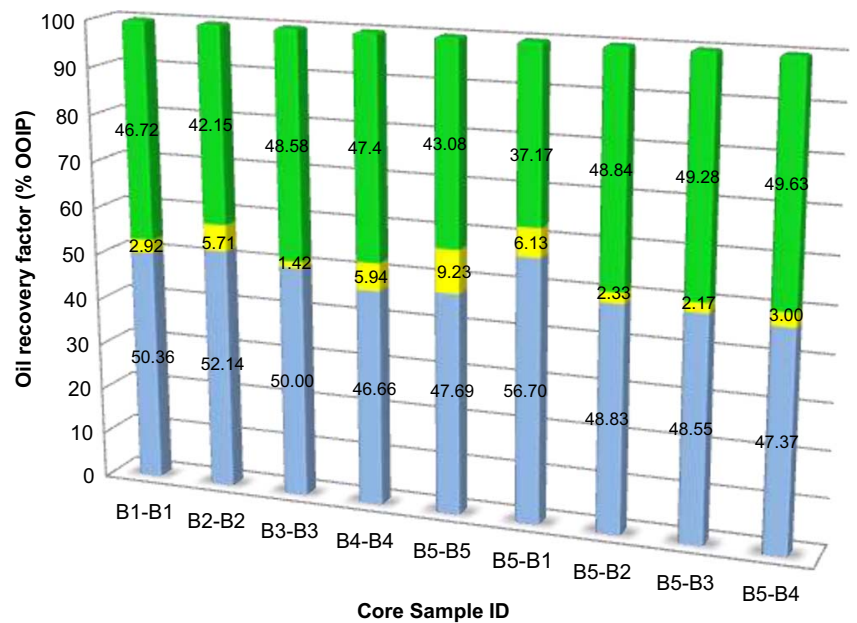

$\square$ LSW Recovery $\square$ LSS Recovery $\square$ Remaining Oil

Fig. 7. Oil recovery from each flooding process for each core.

of the cores have shown consistency and varied around $2.1 \%$ OOIP. As listed in Table 8, more than $90 \%$ of LSW recovery was produced before Water Breakthrough (WBT) which occurred in the first 0.30 to $0.44 \mathrm{PV}$ injection. Further LSW injection after WBT led to small increase in the oil recovery ranged from $3 \%$ to $7 \%$ OOIP. Change in permeability and residual oil saturations are also presented in Table 8.

For a better understanding of LSW impact on recovery factor, a comparison was made between the achieved results of LSW flooding and the traditional (high saline) waterflooding. As shown in Table 9, a maximum of $7 \%$ additional OOIP is expected to be produced as a result of LSW flooding for water-wet rocks. 
Table 8. Summary of experiments.

\begin{tabular}{lccccccccc}
\hline Core ID & B1-B1 & B2-B2 & B3-B3 & B4-B4 & B5-B5 & B5-B1 & B5-B2 & B5-B3 & B5-B4 \\
\hline$S_{\text {wi }}(\mathrm{mD})$ & 0.22 & 0.23 & 0.21 & 0.24 & 0.25 & 0.27 & 0.28 & 0.21 & 0.22 \\
$K_{\text {abs }}(\%$ OOIP) & 176.7 & 217.8 & 172.3 & 177.5 & 154.4 & 198.0 & 191.9 & 285.6 & 300.8 \\
$V_{\mathrm{o}}(\%)$ & 13.51 & 13.40 & 13.90 & 13.93 & 12.84 & 12.83 & 12.75 & 15.10 & 13.50 \\
$K_{\mathrm{o}}\left(\mathrm{S}_{\mathrm{oi}}\right)(\mathrm{mD})$ & 40.30 & 67.71 & 72.70 & 53.76 & 47.69 & 49.80 & 47.05 & 68.04 & 67.24 \\
WBT $(\mathrm{PV})$ & 0.44 & 0.33 & 0.38 & 0.40 & 0.31 & 0.39 & 0.31 & 0.38 & 0.31 \\
WBT recovery (\%OOIP) & 46.71 & 41.42 & 47.85 & 44.44 & 43.84 & 49.80 & 44.96 & 44.92 & 43.61 \\
Time of WBT (min) & 39.6 & 29.7 & 34.2 & 36 & 28.9 & 35.1 & 27.9 & 34.2 & 28.8 \\
LSW recovery (\%OOIP) & 50.36 & 52.14 & 50.00 & 46.66 & 47.69 & 56.70 & 48.83 & 48.55 & 47.37 \\
$S_{\text {or-LSW }}$ & 0.39 & 0.33 & 0.40 & 0.44 & 0.33 & 0.26 & 0.39 & 0.39 & 0.35 \\
LSW Volume injected (PV) & 10 & 10 & 10 & 10 & 10 & 10 & 10 & 10 & 10 \\
$K_{\mathrm{w}}\left(S_{\text {or-LSW })(m D)}\right.$ & 68 & 248 & 72 & 79 & 85 & 45 & 58 & 77 & 114 \\
LSS recovery $(\% O O I P)$ & 2.92 & 5.71 & 1.42 & 5.94 & 9.23 & 6.13 & 2.33 & 2.17 & 3.00 \\
$S_{\text {or-LSS }}$ & 0.36 & 0.28 & 0.39 & 0.40 & 0.30 & 0.23 & 0.37 & 0.38 & 0.33 \\
LSS Volume injected (PV) & 10 & 10 & 10 & 10 & 10 & 10 & 10 & 10 & 10 \\
$K_{\mathrm{w}}\left(S_{\text {or-LSS }}\right)(\mathrm{mD})$ & 144 & 512 & 255 & 342 & 251 & 182 & 309 & 204 & 368 \\
Aging (days) at $80{ }^{\circ} \mathrm{C}$ & 21 & 26 & 21 & 25 & 30 & 25 & 28 & 23 & 26 \\
Final recovery $(\% O O I P)$ & 53.28 & 57.85 & 51.42 & 52.60 & 56.92 & 62.83 & 51.16 & 50.72 & 50.37 \\
\hline
\end{tabular}

Table 9. Comparison of LSW and high saline waterflooding.

\begin{tabular}{lccc}
\hline Injection type & Injection brine & Breakthrough recovery \%OOIP & Final recovery \%OOIP \\
\hline Traditional waterflooding & High saline & 44 & 49 \\
LSW & 10\% High saline & 50 & 56 \\
\hline
\end{tabular}

Key: LS water was obtained by $1 / 10$ dilutions of the brines in the list.

\section{Conclusion}

In this study, through laboratory coreflooding tests, the EOR potential of LSW and LSS floodings have been investigated using nine Berea sandstones core samples. The conclusions from this research study can be shortly presented as follows:

- Surfactant flooding in combination with low salinity water is a new potentially promising hybrid EOR process. The success of this method depends on the selected brines and concentration of the injection brine.

- None of the surfactant solutions was precipitated at $60{ }^{\circ} \mathrm{C}$. Reduction in surfactant solubility was observed with decrease in temperature and increase in salinity concentration in the presence of divalent ions $\left(\mathrm{Ca}^{2+}\right.$ and $\left.\mathrm{Mg}^{2+}\right)$.

- LSS flooding improved the oil recovery up to $9.3 \%$ OOIP where the best combination for LSS flooding was B5-B5. While, the highest oil recovery for LSW injection (52\% OOIP) was obtained in which B2 $\left(9.5 \% \mathrm{NaCl}\right.$ and $\left.0.5 \% \mathrm{MgCl}_{2}\right)$ used for both saturation and coreflooding.
- LSS flooding has the highest efficiency when the salinity is optimum and the reduction in interfacial tension between oil and water is maximum.

- Based on the comparison study, injection of low salinity brine provides higher oil recovery than the traditional waterflooding. The ultimate recovery increases as the salinity of the injection brine decreases (incremental recoveries up to $7 \%$ OOIP).

- During LSW stage, a significant amount of oil (around 90-93\% of lowsal recovery) was produced before the water breakthrough.

- As none of the suggested theories describes all of the observations made during low salinity injection, either there are a number of mechanisms underlying the low salinity effect, or the right mechanism behind the low salinity effect has not yet discovered.

Acknowledgments. The authors are grateful to Norwegian University of Science and Technology for providing the facilities to conduct this research study, and thank Professor Ole Torsaeter and Hamid Hosseinzade Khanamiri for their valuable insight and support. 


\section{References}

1 Martin J.C. (1959) The effects of clay on the displacement of heavy oil by water, SPE-1411-G, in: Venezuelan Annual Meeting, 14-16 October, Caracas, Venezuela, Society of Petroleum Engineers.

2 Bernard G.G. (1967) Effect of floodwater salinity on recovery of oil from cores containing clays, SPE, SPE-1725, in: 38 Annual SPE of AIME California Regular Meeting, 26 October 1967, Los Angeles, CA, USA.

3 Riisoen S. (2012) Effect of combined low salinity and surfactant injection on oil recovery in aged, Master Thesis, University of Bergen, Norway.

4 Zolotukhin A.B., Ursin J.R. (2000) Introduction to petroleum reservoir engineering, Høyskoleforlaget, Norwegian Academic Press, Kristiansand, Norway.

5 Jadhunandan P.P., Morrow N.R. (1995) Effect of Wettability on Waterflood Recovery for Crude Oil/Brine/Rock Systems, SPE Res. Eng. 10, 1, 40-46.

6 Tang G.Q., Morrow N.R. (1997) Salinity, temperature, oil composition, and oil recovery by waterflooding, SPE Res. Eng. 12, 4, 269-276.

7 Tang G., Morrow N.R. (1999) Influence of brine composition and fines migration on crude oil/brine/rock interactions and oil recovery, J. Pet. Sci. Eng. 24, 2-4, 99-111.

8 Tang G., Morrow N.R. (2013) Injection of dilute brine and crude oil/brine/rock interactions, in: P.A.C. Raats, D. Smiles, A.W. Warrick (eds), Environmental mechanics: water, mass and energy transfer in the biosphere, American Geophysical Union, Washington DC, pp. 171-179.
9 Morrow N.R., Tang G., Valat M., Xie X. (1998) Prospects of improved oil recovery related to wettability and brine composition, J. Pet. Sci. Eng. 20, 3-4, 267-276.

10 Morrow N., Buckley J. (2011) Improved oil recovery by lowsalinity waterflooding, SPE JPT 63, 5, 106-112.

11 Filoco P.R., Sharma M.M. (1998) Effect of brine salinity and crude oil properties on relative permeabilities and residual saturations, in: SPE Annual Technical Conference and Exhibition, New Orleans, Louisiana, USA.

12 Skrettingland K., Holt T., Tweheyo M.T., Skjevrak I. (2010) Snorre low salinity water injection - core flooding experiments and single well field pilot, in: SPE Improved Oil Recovery Symposium, Tulsa, Oklahoma, USA.

13 Alagic E. (2010) Combination of low salinity water flooding with surfactant flooding, a new hybrid EOR process, $P h D$ Thesis, University of Bergen, Norway.

14 Tichelkamp T., Vu Y., Nourani M., Oye G. (2014) Interfacial tension between low salinity solutions of sulfonate surfactants and crude and model oils, Energy Fuels 28, 4, 24082414.

15 Torsaeter O. (2003) Experimental reservoir engineering laboratory workbook, Norwegian University of Science and Technology, Department of Petroleum Engineering and Applied Geophysics, Norwegian University of Science and Technology.

16 Hadia N.J., Hansen T., Tweheyo T., Torsaeter O. (2012) Influence of crude oil components on recovery by high and low salinity waterflooding, Energy Fuels 26, 7, 4328-4335.

17 Hankins N.P., Harwell J.H. (1997) Case studies for the feasibility of sweep improvement in surfactant-assisted waterflooding, J. Pet. Sci. Eng. 17, 1-2, 41-62. 